\title{
Antirivers and their role in the biotechnosphere formation
}

\author{
Antonina Suzdaleva ${ }^{1 *}$, Alim Gur'ev ${ }^{2}$ and Valentin Tkachev $^{3}$ \\ ${ }^{1}$ National Research University "MPEI", 111250, Krasnokazarmennaya 14, Moscow, Russia \\ ${ }^{2}$ JSC «Institute Hydroproject», 125993, Volokolamskoe sh., 2, Moscow, Russia \\ ${ }^{3}$ Moscow State University of Civil Engineering, 129337, Yaroslavskoye Shosse 26, Moscow, Russia
}

\begin{abstract}
In the present-day conditions, we need to stop seeing the creation of antirivers as an environmentally hazardous activity. The threat of a global water consumption crisis forces us to build the hydrotechnical systems that will have a significant environmental impact. The scientists' task consists in prompt development of an interdisciplinary approach to their implementation, combining the resolution of technical, environmental and social issues.
\end{abstract}

\section{Introduction}

In the modern world, the ever-growing human impact on water systems takes place on the background of the growing need for water resources. As a result, a deficit of potable water is produced in some regions, which may grow into a global water consumption crisis $[1,2]$. The main direction in the search for the resolution of these issues is to create river flow management systems [3]. However, this method is not applicable for delivering water to the regions where its deficit cannot be compensated by regulating the flow and reducing the water consumption. It is needed to build hydrotechnical systems redistributing water resources among different regions. Similar projects are already implemented in several countries $[4,5,6]$. Recently, a system for artificial transfer of river flow is designated in the scientific literature by the term "antiriver" $[7,8]$.

The creation of antirivers is producing great concern on the part of experts in the field of protection and rational use of water resources [9]. It is fully justified, since the implementation of such projects will inevitably lead to significant changes in the environmental condition of not only the river basins and wide territories surrounding them, but also the sea basins transformed river flows fall into.

However, the content of the term "antiriver" still lacks a clear definition, which generates significant difficulties when evaluating the ecological implications of different projects related to redistribution of river flow.

Russian guidelines [10] developed for the evaluation of the sanitary conditions during the river flow redistribution, that was planned, indicate that an antiriver is a reverse flow water body resulting (including the temporary ones) from the functioning of specialized hydrotechnical facilities. A detailed interpretation of the term allows to apply it in a quite

* Corresponding author: SuzdalevaAL@yandex.ru 
wide range of meanings; however, it excludes from the antirivers category a significant part of projects the implementation of which is associated with similar ecological implications. From the ecological point of view, the term "antirivers" basically means a river flow transfer resulting in a considerable volume of natural water entering another geographical area (basin, region, etc.), and not the appearance of a reverse flow as such. At the same time, the river flow along the natural channel is reduced, and this is what causes the need to apply the term "antiriver" to all these projects. Based on the definition given above we can consider an "antiriver" a short-term change in the water movement within any limited river section, the effect of which will not go beyond the local scale. Therefore, a clearer and wider definition of this term is needed. Otherwise, if the project contemplates the movement of water in reverse direction along the natural channel, it will be an "antiriver". But if a transfer of the same volume of water is performed by draining water through a channel, it is a "flow redistribution". From the ecological point of view, the implications of these types of activity are equal, but the interpretation and the public resonance may differ fundamentally.

It is appropriate to accept the process aimed at creating similar facilities, namely transfer of the river flow, as the basis of the term "antiriver". However, by no means all types of river flow redistribution may be considered as antirivers. Based on the functions to fulfill, the transfer systems are conditionally divided into three categories [11]:

- intrabasin or local ones: when the transfer system does not go beyond the given river;

- interbasin ones: connecting adjacent river basins;

- interregional and interzonal ones: connecting the river systems of different physical and geographical regions (climatic zones).

Flow transfer systems are also classified based on the scale of the water resources involved [11]. Small transfers may include complexes with anannual volume of flow transfer of up to $1 \mathrm{~km}^{3}$, the medium ones from 1 to $5 \mathrm{~km}^{3}$, the large ones over $5 \mathrm{~km}^{3}$. It is obvious that only the latter should be considered as antirivers.

The fact that the flow transfer system is represented by a controlled natural and technical system (NTS) [12] needs to be considered when evaluating the ecological implications of the creation of antirivers. It is formed by natural and technical facilities the work of which is interrelated and interdependent. The regime of water discharge is determined not only by the needs of the business activity, but by the need to maintain favorable environmental and sanitary conditions, and to provide other aspects of the lifesustaining activity of the population. Based on the above, the following definition can be given: an antiriver is a controlled NTS created for a large-scale interbasin and interregional transfer of water flow.

The controllability of the NTS created on the basis of antiriversis, generally, one-sided in nature and consists in controlling the volumes of water being redistributed. However, the creation of antirivers may be justified environmentally, only if the scope of the NTS control includes timely and efficient influence on all the main environmental components, including soil and vegetation cover and the wildlife. The control of both donor water course regions and recipient water course regions is carried out for the purpose of their maintenance and protection from unfavorable external factors. The latter should include the impact of unfavorable hydrometeorological factors (floods, draughts), the strength and the frequency of which are growing steadily due to global climatic changes. It is obvious that such view implies rethinking of not only the content of the concept of «antirivers», but their roles as well. This, in turn, is impossible without giving up some common stereotypes of thinking which can be overcome only by consistently implanting the innovative approaches to resolving issues [13] in the mind of the scientific community. The main stereotype, which was without any doubt, justified in the past, is the idea of antirivers exclusively as 
facilities of hydrotechnical construction performed for obtaining commercial benefit while ignoring catastrophic ecological implications.

The second stereotype concerns the foundations of the methodological basis of the environmental safety strategy. At the present stage, there is a traditional prohibitive and isolationist approach to resolving issues in this field. Its essence consists in the prohibition of the activity having a negative environmental impact, as well as in the attempts to isolate the protected natural areas from such impact. Such methodology was efficient in the previous period, when the impact of the industrial activity was local. The processes of selfpurification and self-regeneration of natural ecosystems protecting them from unfavorable external impacts could maintain their good condition. At present, on many occasions, the natural homeostasis mechanisms cannot perform their function; as the result, environmental degradation is being registered everywhere. The biosphere is practically transformed into biotechnosphere, the condition of which depends on human factors. Global climatic changes that take place affecting all ecosystems of the planet play a special role in this process. In these conditions, a need of development of an alternative environmental protection strategy [12] arises. It is based on the use of different scale controlled NTS. The end purpose of the development of this strategy is a transition from an uncontrolled biotechnosphere to a controlled biotechnosphere which represents a hierarchy of functionally interrelated controlled NTS. Its prototypes are the existing hydraulic power systems. They regulate not only the river flow, but the pollutant flux as well, provide sanitary and ecological discharges aimed at maintaining good conditions for the existence of people and nature areas, and protect them from emergency situations. Thus, the implementation of ecologically justified antiriver projects will allow to control the processes of the biotechnosphere at a higher, interbasin, and interregional level.

\section{Conclusion}

The above materials can be summarized as follows:

1. The separation of the concepts of "antiriver" and "interbasin (interzonal) flow redistribution" is not inappropriate from the environmental point of view. The dissociation of these terms only reflects the specific character of the engineering solutions aimed achieving the same end results; in the present-day world, the creation of an international market of fresh water resources is becoming the main of them.

2. The antirivers are initially created as controlled NTS, but this fact itself is not fully recognized at present. For this reason, the antirivers projects are being considered as purely technical. Their practical implementation is evaluated from the perspectives of economic and geopolitical benefit. The environmental component of such projects is considered as a side effect. Such view of the issue is usual for both "technocrats" and "environmentalists". The difference between these two positions is that the first ones are trying to downgrade the role of the ecological implications (or partially ignore them), and the second ones are trying to justify their significance and achieve the prohibition of the project implementation. Based on the historical experience, we can forecast for certain that the victory of the economical, and especially geopolitical expediency is just a matter of time. This dictates the need to develop a constructive approach to resolving the issue on the interbasin river flow redistribution that would be ahead of the implementation of the projects, including the ecological optimization of the significant aspects of the technogenesis.

3. The development of the antiriver projects must include an evaluation of the ways and possibilities of their ecological optimization [14-16], which means a system of measures aimed at reducing the significant negative environmental aspects of the outlined activity, while increasing the efficiency of the positive ones (for example, protection from extreme hydrometeorological fluctuations). Development of a justified prohibition of the projects 
able to result in environmental catastrophes and their replacement by alternative options the environmental risks of which could be considered as admissible should be considered as one of the types of ecological optimization.

\section{References}

1. 1. M.A. Duda, M.T. El-Ashry, Water In., 25, 115-126 (2000)

2. V.I. Danilov-Danilyan, K.S. Losev, Water consumption: ecological, economic, social and politic aspects (Moscow, Nauka, 2006)

3. B.D. Richter, R. Mathews, D.L. Harrison, R. Wigington, Ec. App., 13, 206-224 (2003)

4. G. Golubev, A.K. Biswas, ICID Bulletin, 28, 18-22 (1979).

5. K.S.S. Murthy, Interregional Water Transfers: Projects and Problems, 117-125 (Luxembourg, 1979)

6. F. Quin, Alberta symposium on Interbasin Water Transfers, 1-14 (Edmonton, 1980)

7. A. Suzdaleva, S. Goryunova, Technogenesis and degradation of surface water objects (Moscow, ID ENERGIYA, 2014)

8. A.L. Suzdaleva, Power Tech. and Eng., 9, 48-54 (2015)

9. P.P. Micklin, EOS Trans., Amer. Geophys. Union, 62, 489-493 (1981)

10. Guidelines for the study of the sanitary conditions of water use under the territorial redistribution of the river flow. Approved 31.03. 2685-83, 22, (1983)

11. A.S. Berezner, Water transfer in the european part of the RSFSR (Leningrad, Hidrometeoizdat, 1985)

12. M.P. Fedorov, A.L. Suzdaleva, Power Tech. and Eng., 3, 10-15 (2014)

13. A.L. Suzdaleva, S.V. Goryunova, Biosphere, 7, 429-449 (2015)

14. A.L. Suzdaleva, V.N. Beznosov, Elshaer Hayam, Hydr. Eng., 4, (2010) - 1, 22-25 (2011)

15. Z. Ivanova, O. Yudenkova, J. Naimaviciene, MATEC Web of Conferences, 73 (2016)

16. G. Potasheva, MATEC Web of Conferences, 73 (2016) 